\title{
OTIMIZAÇÃO DA SÍNTESE DE HIDROGÉIS NANOCOMPÓSITOS INTERCALADOS PARA POSSÍVEL APLICAÇÃ̃ NA ÁREA MÉDICA
}

\author{
Renan S. Fernandes, Marcia R. de Moura e Fauze A. Aouada* \\ Grupo de Compósitos e Nanocompósitos Híbridos (GCNH), Faculdade de Engenharia de Ilha Solteira, UNESP - Universidade \\ Estadual Paulista, Programa de Pós-graduação em Ciência dos Materiais, 15385-000 Ilha Solteira - SP, Brasil
}

Recebido em 19/05/2016; aceito em 25/07/2016; publicado na web em 16/08/2016

\begin{abstract}
OPTIMIZATION OF SYNTHESIS OF INTERCALATED NANOCOMPOSITE HIDROGELS FOR FUTURE APPLICATION IN THE MEDICAL AREA. In this study, the hydrogel formulations based on polysaccharide sodium alginate were investigated for further development of intercalated nanocomposite hydrogels, for purposes of future applications in the areas of health as a carrier in drug delivery systems. Thus, the objective of the work dealt with in the optimization of hydrogels synthesis and obtaining nanostructured hydrogels with clay in an intercalated conformation. The optimization of the hydrogel synthesis was successful, and it is possible to define the materials and / or solutions to be used and concentrations of these solutions to the best formulations of hydrogels. The choice of the concentration of the polysaccharide, the type of crosslinking agent and nanofiller to continued development work, it was determined following criteria as the degree of swelling, and in some cases the physical properties, contributed to determine the best hydrogels. The development of intercalated nanocomposites hydrogel beads was confirmed by the $\mathrm{X}$-ray diffraction technique, which thus could be used to observe evidence of effective incorporation or intercalation of the nanoclay in the hydrogel matrix.
\end{abstract}

Keywords: hydrogels; nanocomposites; sodium alginate; nanofillers; intercalation.

\section{INTRODUÇÃO}

Tendo em vista a necessidade de equipamentos sofisticados na área biomédica, os que são disponibilizados para utilização apresentam alto custo, sendo este um impasse no que diz respeito à aquisição. Deste modo, os biomateriais surgem como uma opção interessante, já que desde a última década vem se estudando e trabalhando com este tipo de material, principalmente na área médica. Existem diferentes maneiras de se definir o termo biomateriais. Dentre essas, os biomateriais são definidos como materiais utilizados na substituição de algum órgão vital que perdeu sua atividade no organismo. Atualmente o campo de aplicação engloba desde as próteses até a utilização para regeneração óssea. ${ }^{1}$ Dentro da classe dos biomateriais, existem os polímeros, que são macromoléculas que se permitem serem moldadas de acordo com a área a ser empregada. ${ }^{2}$ A utilização de polímeros está em ascendência, e se mostra altamente proveitoso na biomedicina principalmente quando se trata de polímeros naturais. A motivação está fundamentada nas propriedades como biodegradabilidade e biocompatibilidade. Dessa maneira, o alginato de sódio (sendo um polímero natural), em razão das propriedades já mencionadas e pelo fato de ser atóxico, termoestável e de baixo custo, vem recebendo grande atenção para tal finalidade. ${ }^{3}$

O alginato de sódio é um polissacarídeo obtido por meio da extração de algas marrons (Phaeophyceae). As cadeias macromoleculares são lineares com segmento rígidos e flexíveis. ${ }^{4} \mathrm{O}$ segmento rígido é atribuído aos blocos $\mathrm{G}$ formado pelo monossacarídeo ácido $\alpha$-L-gulurônico e o segmento flexível está associado aos blocos $\mathrm{M}$ que são constituídos de unidades monossacarídicas de ácido $\beta$-D-manurônico. ${ }^{4} \mathrm{O}$ alginato de sódio pode apresentar cadeias com apenas blocos $\mathrm{M}$ ou apenas blocos $\mathrm{G}$, ou pode ser constituída por uma mistura deles, como ilustrado na Figura 1. A relação desses blocos depende da fonte a qual o alginato é obtido. ${ }^{5}$

*e-mail: faouada@yahoo.com.br

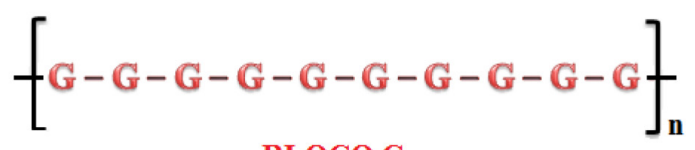

BLOCO G
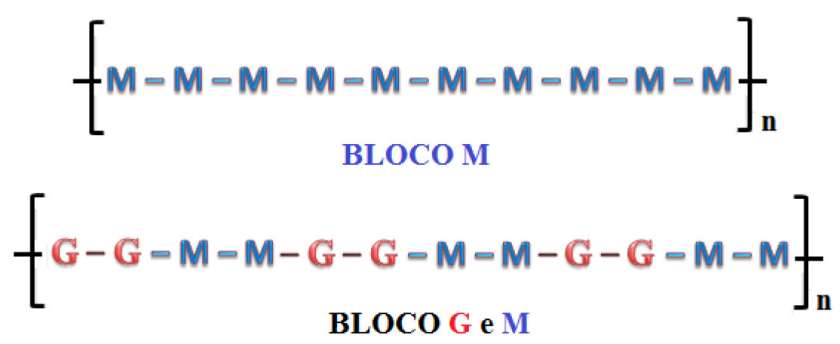

Figura 1. Representação da maneira como os blocos podem estar dispostos na cadeias polimérica

O polímero alginato de sódio apresenta também uma característica importante para a formação praticamente instantânea de hidrogéis. Quando inseridos em meio contendo íons bi ou trivalentes $\left(\mathrm{Ca}^{2+}, \mathrm{Ba}^{2+}, \mathrm{Fe}^{2+}, \mathrm{Fe}^{3+}, \mathrm{Al}^{3+}\right)$, há uma espontaneidade na formação de hidrogéis devido à forte interação entre alginato-íons reticuladores. A conformação do alginato reticulado com íons divalentes é chamada de "caixa de ovos", na qual os blocos G interagem com os íons divalentes e essa interação faz com que os blocos $\mathrm{G}$ fiquem próximos e paralelos entre si, similar a uma caixa de ovos. Essa reticulação ainda possibilita a melhora de propriedades como resistência mecânica, coesão, rigidez, de barreiras a vapores, entre outras. ${ }^{6}$ Além disso, a incorporação de materiais compatíveis à matriz dos hidrogéis à base do polissacarídeo alginato de sódio pode melhorar as propriedades, principalmente, de sorção e dessorção dos hidrogéis. Neste contexto, as nanocargas, como a nanoargila e as zeólitas, tornam-se uma opção devido as suas propriedades hidrofílicas e de sorção de solutos de diferentes propriedades químicas. 
As argilas são minerais formados por meio de processos geológicos naturais. ${ }^{7}$ São quimicamente estruturados por camadas tetraédrica de $\mathrm{SiO}_{4}$ e camadas octaédricas de Al, Mg e/ou Fe hidratadas. ${ }^{8,9}$ São ditos materiais nanométricos (ou nanoargila, nos quais as folhas ou camadas estruturais apresentam dimensões na ordem de $1 \mathrm{~nm}$ ) e sob essas dimensões associam suas propriedades como capacidade de troca iônica, habilidade de absorção, capacidade de expansão entre outras. De acordo com Carretero, ${ }^{10}$ há sinais que em períodos anteriores espécies como Homo neanderthalensis e Homo erectus estabeleciam misturas entre água e argila para utilização em curativos, limpeza de pele e possíveis irritações. Atualmente o uso das nanoargilas tem se expandido e para utilização na área biomédica o atrativo é a inércia química e a atoxidade. Quando incorporado aos materiais, as nanoargilas podem estar conformadas de forma intercalada, esfoliada ou então uma mistura de ambas as maneiras. ${ }^{11}$

Já as zeólitas, consideradas aluminossilicatos hidratados, são bastante utilizadas em tratamento de efluentes, catálise, por apresentarem propriedades como: capacidade de troca iônica, adsorção de gases, capacidade de inchamento e adsorção elevada. ${ }^{12,13}$ Além disso, pelo fato de serem atóxicas, as zeólitas são materiais com grande potencialidade de aplicação na área da saúde. As zeólitas são constituídas por tetraedros de $\mathrm{SiO}_{4}$ e $\mathrm{AlO}_{4}$ nos quais o átomo que liga um tetraedro ao outro é o oxigênio. Pelo exposto, a utilização de zeólitas como cargas em nanocompósitos é bastante promissora. ${ }^{12,13}$

Hidrogéis são polímeros hidrofílicos reticulados tridimensionalmente, sendo capazes de absorver elevada quantidade de água em sua estrutura sem se dissolver. ${ }^{14}$ Quando intumescidos os hidrogéis se assemelham aos tecidos vivos pela quantidade de água existente em sua estrutura, além do que, o aspecto físico (elasticidade e maciez) reduz inflamações que são oriundas das reações com outras células. Por sua vez, a hidrofilicidade é o fator determinante dos hidrogéis e essa característica está associada aos grupos funcionais hidrofílicos (tais como hidroxilas, carboxilas, amidas, entre outros) presentes na cadeia polimérica. ${ }^{15,16}$ Quando o objetivo é a liberação controlada, os hidrogéis são considerados promissores para esta aplicação pelo fato de possuírem características tais como biodegradabilidade, biocompatibilidade, hidrofilicidade, estabilidade química, capacidade de sorção e dessorção de diferentes solutos. Estes sistemas, no caso da biomedicina, visam manter a concentração do fármaco em níveis efetivos, com a intenção de proporcionar a continuidade ao tratamento terapêutico, evitando a repetições de administração (aplicação) do fármaco, diminuindo o custo e efeitos colaterais decorrente de altas concentrações presentes na corrente sanguínea. ${ }^{17}$

$\mathrm{Na}$ literatura há alguns trabalhos empregando hidrogéis nanocompósitos como veículos carreadores para sistemas de liberação controlada. Por exemplo, Zhou et al. ${ }^{18}$ desenvolveram hidrogéis nanocompósitos superabsorventes à base de nanofibras de celulose carboxiladas (CCNFs) e carboximetilcelulose-g-poli(ácido acrílico-co-acrilamida). Os autores concluíram que fatores como quantidade de CCNFs, tipo de sal, temperatura e $\mathrm{pH}$, influenciam diretamente nas propriedades físico-química dos hidrogéis desenvolvidos. Os resultados mostram que com a adição de $2,5 \%$ de CCNFs, a capacidade de absorção de água aumentou de 245,8 para 458,7 g/g. Em outros estudos, Gonzalez et al. ${ }^{19}$ produziram hidrogéis nanocompósitos de poli(álcool vinílico)/nanofibras de celulose e investigaram a utilização destes como curativo em feridas. Os autores observaram que a incorporação de nanofibras melhorou as propriedades mecânicas e de barreiras contra bactérias, o que impossibilitou a penetração de bactérias na pele durante 15 dias. Yadollahi et al. ${ }^{20}$ desenvolveram hidrogéis nanocompósitos a base de carboximetilcelulose/ZnO e estudaram sua potencialidade na área médica. Os hidrogéis nanocompósitos exibiram intumescimento maior que os hidrogéis puros e sua atividade antimicrobiana foi considerada eficiente contra bactérias E. coli (gram-negativa) e S. aureus (gram-positiva).

Os objetivos deste trabalho foram otimizar e aperfeiçoar a síntese de grânulos micrométricos (ou microesferas) de hidrogéis a base do polissacarídeo alginato de sódio de maneira rápida e reprodutível, visto que a literatura reporta com maior intensidade a obtenção desses hidrogéis em forma de membrana. Após essa primeira etapa, foram otimizadas as sínteses de hidrogéis nanocompósitos contendo nanoargila e/ou zeólita em relação a sua capacidade de absorção de água (propriedades hidrofílicas) e estruturais, visando sua futura aplicação na área médica.

\section{PARTE EXPERIMENTAL}

\section{Preparo de soluções}

\section{Preparo de soluções de alginato de sódio}

As soluções do polissacarídeo alginato de sódio (Cromoline® Química Fina) foram obtidas nas concentrações de 1 e $2 \%$ m/v. Após a adição total do alginato, a solução ficou sob agitação magnética contínua por aproximadamente $4 \mathrm{~h}$. Em seguida, as soluções foram armazenadas na geladeira para remoção das bolhas.

\section{Preparo de dispersões de nanoargila e zeólita}

As dispersões de nanoargila Cloisita- $\mathrm{Na}^{+}$(Southern Clay Products) foram obtidas nas concentrações de $1,2,5$ e $5 \%$ e para o alginato a concentração foi de $2 \% \mathrm{~m} / \mathrm{v}$. A dispersão de nanoargila ficou por 30 min sob agitação magnética contínua. Em seguida, foi levada a um agitador ultrassônico de ponta no qual passou por 5 ciclos de ultrassom, cada ciclo equivalente a $1 \mathrm{~min}$ com $50 \%$ de frequência. Após isso, a dispersão retornou para o agitador magnético e sobre esta adicionou-se de alginato de sódio. A dispersão ficou por aproximadamente $4 \mathrm{~h}$ sob agitação magnética e então foi armazenada em geladeira. Para as concentrações de 2,5 e 5\% de nanoargila o procedimento utilizado foi o mesmo.

Preparou se uma dispersão de zeólita a $5 \% \mathrm{~m} / \mathrm{v}$, e uma dispersão contendo as duas nanocargas nas concentrações de $2,5 \% \mathrm{~m} / \mathrm{v}$ para ambas. O procedimento utilizado foi o mesmo descrito nesta seção. A zeólita utilizada neste trabalho foi a clinoptilolita ZK406, que possui densidade de carga superficial de aproximadamente $10,1 \times 10^{-23} \mathrm{meq} / \AA^{2}$, com capacidade de troca catiônica entre 0,8 a $1,2 \mathrm{meq} / \mathrm{g}$ e seus poros apresentam diâmetro entre 4 à $7 \AA$ (dados fornecidos pelo fabricante St. cloud zeolite).

\section{Preparo de soluções reticuladoras}

Prepararam-se soluções de cloreto de cálcio (Sigma-Aldrich) e cloreto de alumínio (Sigma-Aldrich) nas concentrações de 1, 2,5 e $5 \% \mathrm{~m} / \mathrm{v}$. As soluções foram obtidas por agitação magnética, sendo então armazenadas em geladeira.

\section{Síntese dos hidrogéis}

Síntese dos grânulos de hidrogéis de alginato de cálcio e alginato de alumínio

Em três béqueres, colocou-se de forma individualizada as soluções de cloreto de cálcio $(1,2,5$ e $5 \%$ m/v), e sobre essas soluções salinas gotejaram-se controladamente, com o auxilio de uma bomba de seringa (New Era modelo NE-300), $10 \mathrm{~mL}$ da solução de $1 \% \mathrm{~m} / \mathrm{v}$ de alginato de sódio a $30 \mathrm{~mL} \mathrm{~h}^{-1}$. Os grânulos formados ficaram por $2 \mathrm{~h}$ na solução salina para o processo de reticulação. Em seguida, os grânulos foram coletados por filtração, lavados com água destilada e colocados em um béquer, por 24 horas, contendo $50 \mathrm{~mL}$ de água destilada para remoção das espécies que não reagiram durante a 
síntese. Após o tempo de 4 h, os grânulos foram separados em placa de acrílico e placa de Petri para secagem a temperatura ambiente. Após a secagem foram armazenados em um recipiente com sílica. $\mathrm{O}$ mesmo procedimento foi realizado para preparar hidrogéis com $2 \%$ $\mathrm{m} / \mathrm{v}$ de alginato de sódio em diferentes reticulantes.

Para a síntese dos grânulos (ou microesferas) de hidrogéis de alumínio a metodologia foi a mesma utilizada para obtenção das microesferas de alginato de cálcio, mudando apenas a solução salina reticuladora.

\section{Síntese dos grânulos de hidrogéis nanocompósitos}

Em três béqueres foram adicionadas as respectivas concentrações de $\mathrm{CaCl}_{2}: 1,2,5$ e $5 \% \mathrm{~m} / \mathrm{v}$. Sobre a solução salina reticuladora gotejou-se controladamente a dispersão de $2 \% \mathrm{~m} / \mathrm{v}$ alginato de sódio + $1 \% \mathrm{~m} / \mathrm{v}$ de argila e os grânulos formados ficaram por $2 \mathrm{~h}$ em solução de $\mathrm{CaCl}_{2}$ sob agitação magnética para completa reticulação. Em seguida, os grânulos foram coletados por filtração, lavados e colocados em um béquer contendo $50 \mathrm{~mL}$ de água destilada durante 4 horas sob agitação magnética contínua para remover os íons em excesso. Após isso, os grânulos foram coletados por filtração novamente e separados em placa de acrílico para secagem em temperatura ambiente.

Para as formulações: $2 \%$ alginato de sódio $+2,5 \%$ de argila e $2 \%$ alginato de sódio $+5 \%$ argila, $2 \%$ alginato $+5 \% \mathrm{~m} / \mathrm{v}$ de zeólita e $2 \%$ alginato $+2,5 \% \mathrm{~m} / \mathrm{v}$ de ambas as nanocargas. O procedimento utilizado foi o mesmo descrito nesta seção.

\section{Grau de intumescimento $(Q)$}

A propriedade hidrofílica dos hidrogéis foi determinada pela medida do grau de intumescimento, utilizando-se água como meio de intumescimento. Foram medidas as massas dos grânulos secos, que foram posteriormente imersos em béqueres contendo $20 \mathrm{~mL}$ de água sob agitação magnética durante 24 h. Após as 24 h, os grânulos foram coletados por filtração e secos superficialmente, e suas massas medidas novamente. Cada medida corresponde à somatória do grau de intumescimento de pelo menos 50 microesferas. Tal metodologia foi adotada pelo fato dessas possuírem uma massa seca bem pequena, o que poderia ocasionar erros experimentais.

Os valores de intumescimento $(\mathrm{g} / \mathrm{g})$ foram determinados com base na equação 1 , dada pelo quociente da massa intumescida $(\mathrm{M} t)$ pela massa seca $(\mathrm{M} s)$ :

$$
\mathbf{Q}=\frac{\mathbf{M t}}{\mathbf{M s}}
$$

$\mathrm{E}$ os valores de intumescimento em porcentagem $(\mathrm{Q} \%)$ foram determinados a partir da equação 2 :

$$
Q \%=\frac{M t-M s}{M s} \times 100
$$

\section{Difração de raios-X (DRX)}

A técnica de DRX foi utilizada para determinar a propriedade estrutural dos hidrogéis e investigar o arranjo (intercalado ou esfoliado) da nanoargila cloisita- $\mathrm{Na}^{+}$na matriz do hidrogel. Os hidrogéis foram macerados e colocados em porta amostras de vidro e posicionados no equipamento. As curvas exibidas nos difratogramas foram obtidas pelo difratômetro de raios-X (Shimadzu, modelo XRD - 6000). Utilizou-se uma fonte de raios-X de $\mathrm{Cu}$ (cobre); $\lambda=0,154 \mathrm{~nm}$; voltagem $=30 \mathrm{kV}$; corrente $40 \mathrm{~mA}$; intervalo angular $2 \theta$ de $4-50^{\circ}$ e velocidade de varredura $1 \% \mathrm{~min}$
O espaçamento interlamelar (d) das amostras foi determinado por meio da lei de Bragg, mostrado na equação 3:

$$
n \lambda=2 d \operatorname{sen} \theta
$$

sendo $\mathrm{n}=$ número inteiro de comprimento de onda; $\lambda=$ comprimento de onda da radiação incidente $(\mathrm{Cu}) ; \theta$ representa o ângulo de incidência que é medido entre o feixe incidente e o plano da amostra.

\section{RESULTADOS E DISCUSSÃO}

\section{Grau de intumescimento $(\mathbf{Q})$}

Sendo a propriedade mais considerável, o grau de intumescimento dos hidrogéis é dependente de muitos fatores. Tais condições podem aumentar ou diminuir o grau de intumescimento dos hidrogéis. Assim, neste trabalho algumas condições e/ou fatores foram testados a fim de determinar a melhor formulação fundamentado no grau de intumescimento.

\section{Influência da concentração do polissacarídeo alginato de sódio e} da concentração do agente reticulador

As concentrações do alginato de sódio foram testadas em 1 e $2 \%$ $\mathrm{m} / \mathrm{v}$ e foi determinada, por meio de medidas de intumescimento, a concentração mais satisfatória. A Tabela 1 apresenta os valores de intumescimento para ambas as concentrações dos hidrogéis a base do polissacarídeo reticulados com $\mathrm{Ca}^{2+}$.

Tabela 1. Valores do grau de intumescimento dos grânulos de hidrogéis sintetizados com diferentes concentração do polissacarídeo alginato de sódio reticulados com $\mathrm{CaCl}_{2}$ com três concentrações distintas

\begin{tabular}{ccccc}
\hline \multicolumn{5}{c}{ Grânulos de hidrogéis de alginato de cálcio } \\
\hline \multirow{2}{*}{$\begin{array}{c}{\left[\mathrm{CaCl}_{2}\right] \%} \\
(\mathrm{~m} / \mathrm{v})\end{array}$} & \multicolumn{2}{c}{$1 \% \mathrm{~m} / \mathrm{v}$ alginato } & \multicolumn{2}{c}{$2 \% \mathrm{~m} / \mathrm{v}$ alginato } \\
\cline { 2 - 5 } & $\mathrm{Q}(\mathrm{g} / \mathrm{g})$ & $\mathrm{Q}(\%)$ & $\mathrm{Q}(\mathrm{g} / \mathrm{g})$ & $\mathrm{Q}(\%)$ \\
\hline 1 & 1,55 & 55,0 & 1,57 & 57,0 \\
2,5 & 1,45 & 47,3 & 1,37 & 37,5 \\
5 & 1,39 & 39,6 & 1,27 & 27,5 \\
\hline
\end{tabular}

Para ambas as concentrações de alginato o grau de intumescimento diminui com o aumento da concentração de cloreto de cálcio $\left(\mathrm{CaCl}_{2}\right)$, isto é, devido à formação das redes poliméricas tridimensionais e do caráter químico deste sal. O cloreto de cálcio é um eletrólito forte e todo eletrólito desta natureza tem o poder de dissociar-se $100 \%$. Deste modo, quanto maior for a concentração do $\mathrm{CaCl}_{2}$, existirão mais íons $\mathrm{Ca}^{2+}$ livres que poderão se ligar aos grupos carboxílicos e hidroxilas presentes no alginato por meio de ligações secundárias.

Observa-se que em concentrações iguais a $1 \% \mathrm{de} \mathrm{CaCl}_{2}$, os valores de intumescimento para os grânulos sintetizados com $2 \%$ de alginato de sódio são ligeiramente mais elevados quando comparados aos grânulos sintetizados com $1 \%$. Este resultado pode estar evidenciando que na cadeia polimérica do alginato em concentração maior existem mais grupamentos hidrofílicos - $\mathrm{COO}^{-}$e $\mathrm{OH}^{-}$, e esses grupamentos são espécies que sofrem interações com as moléculas de água no processo de intumescimento.

Por outro lado, nas concentrações de 2,5 e $5 \%$ de $\mathrm{CaCl}_{2}$, os grânulos de $2 \%$ de alginato apresentam grau de intumescimento menores em relação aos grânulos com $1 \%$. Com o aumento da concentração do agente reticulador, os grupamentos hidrofílicos que por ventura estariam livres, estão se ligando com os íons $\mathrm{Ca}^{2+}$, formando redes poliméricas tridimensionais. Essas redes diminuem as dimensões dos 


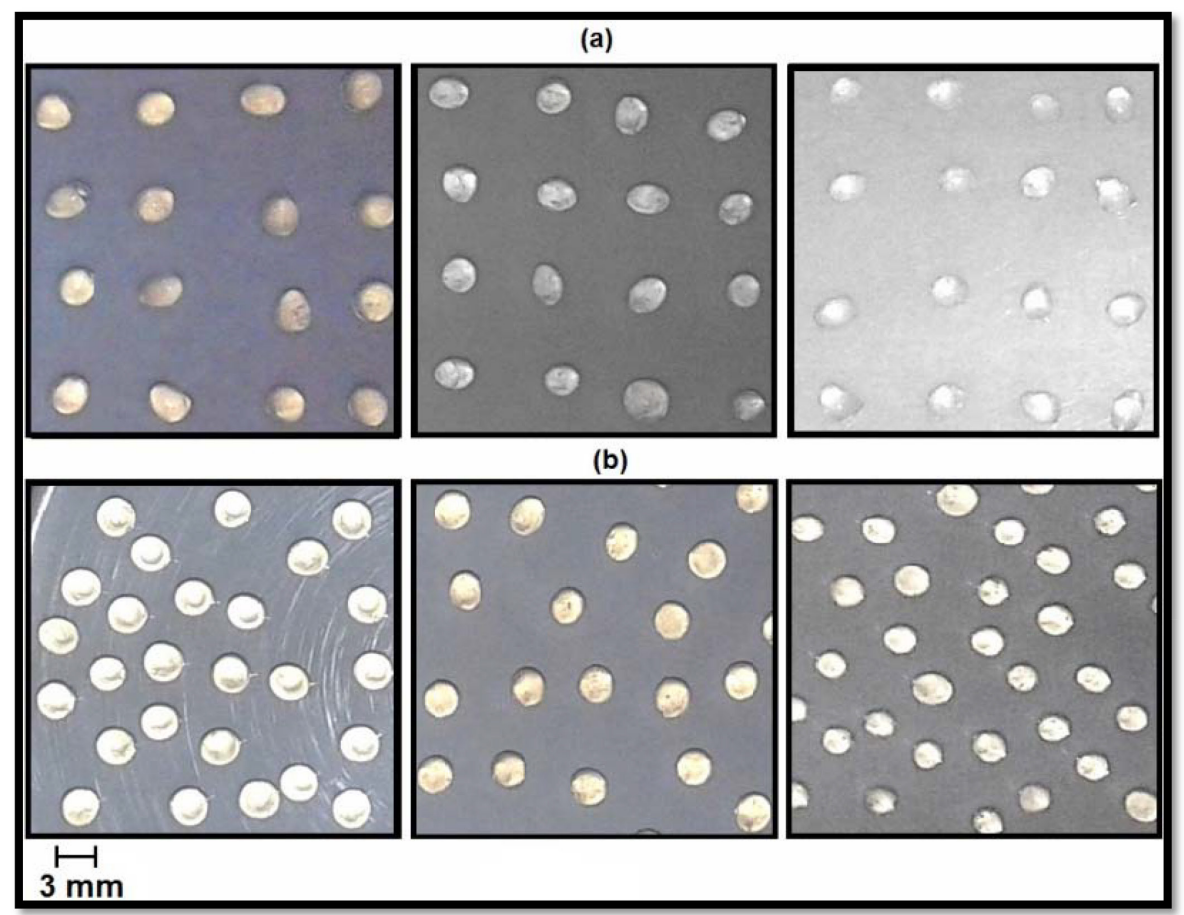

Figura 2. Fotografias digitais capturadas após o processo de purificação dos hidrogéis. (a) imagens de hidrogéis 1\%; (b) hidrogéis $2 \%$ de alginato de cálcio. As concentrações de cálcio aumentam da esquerda para a direita de ambas as imagens variando de 1, 2,5 e 5\% ( $\mathrm{m} / \mathrm{v})$

poros estruturais e refletem em um hidrogel mais reticulado, com menor capacidade de expansão e consequentemente menor grau de intumescimento. Esse aumento da concentração de $\mathrm{CaCl}_{2}$ ocasiona o aumento na densidade de reticulação, sendo assim, quanto maior a densidade de reticulação, mais reticulada será a cadeia polimérica, impedindo assim a expansão em volume desejada. ${ }^{21,22}$

A concentração de $2 \% \mathrm{~m} / \mathrm{v}$, mesmo apresentando grau de intumescimento menor em algumas condições experimentais, foi escolhida para dar sequência no trabalho pelo fato de apresentar homogeneidade no tamanho e todas as amostras apresentarem forma esférica, diferente das amostras $1 \% \mathrm{~m} / \mathrm{v}$, que não apresentavam forma esférica e possuíam deformações, como observado na Figura 2. Portanto, a forma esférica está provavelmente relacionada com a viscosidade da solução.

\section{Influência do agente reticulador}

Os agentes reticuladores testados para síntese dos hidrogéis foram o cloreto de cálcio e o cloreto de alumínio. Na Tabela 2 estão apresentados os valores do grau de intumescimento para hidrogéis sintetizados com $2 \%$ de alginato de sódio em 3 concentrações diferentes desses agentes. Como destacado anteriormente, há uma tendência em diminuir o grau de intumescimento quando aumenta-se a concentração do agente reticulador.

No caso dos grânulos de hidrogéis reticulados com alumínio (hidrogéis de alginato de alumínio), esses apresentaram grau de intumescimento maior que os hidrogéis de alginato de cálcio, sendo que esta propriedade não foi afetada pela concentração do íon $\mathrm{Al}^{3+}$. O grau de intumescimento dos hidrogéis de alumínio é maior devido o alumínio ser um íon de valência $3^{+}$, assim, este apresenta maior densidade de carga positiva, tendo potencialidade de se ligar com 3 grupamentos hidrofílicos.

Deste modo, é provável que a velocidade de reticulação do alumínio seja maior que a do cálcio, que possui valência $2^{+}$. Acredita-se que, pelo fato dessa velocidade ser maior, a reticulação do alumínio com os grupamentos característicos do alginato possibilita espaços vazios entre as cadeias do alginato. Tais vazios se tornam propícios para o armazenamento das moléculas de água. Na Figura 3, é proposto pelos autores um modelo para entendimento deste fenômeno.

Tabela 2. Dados do grau de intumescimento de hidrogéis sintetizados com $2 \% \mathrm{~m} / \mathrm{v}$ de alginato de sódio em três concentrações distintas dos agentes reticuladores

\begin{tabular}{ccccc}
\hline \multirow{2}{*}{$\begin{array}{c}{\left[\mathrm{CaCl}_{2}\right] \text { ou }\left[\mathrm{AlCl}_{3}\right] \%} \\
(\mathrm{~m} / \mathrm{v})\end{array}$} & \multicolumn{2}{c}{$\begin{array}{c}\text { Hidrogéis de alginato } \\
\text { de cálcio }\end{array}$} & \multicolumn{2}{c}{$\begin{array}{c}\text { Hidrogéis de alginato } \\
\text { de alumínio }\end{array}$} \\
\cline { 2 - 5 } & $\mathrm{Q}(\mathrm{g} / \mathrm{g})$ & $\mathrm{Q}(\%)$ & $\mathrm{Q}(\mathrm{g} / \mathrm{g})$ & $\mathrm{Q}(\%)$ \\
\hline 1 & 1,57 & 57,0 & 1,64 & 64,1 \\
2,5 & 1,37 & 37,5 & 1,53 & 52,9 \\
5 & 1,27 & 27,5 & 1,80 & 80,7 \\
\hline
\end{tabular}

Além disso, notou se que os hidrogéis de alginato de alumínio não apresentavam forma esférica, eram deformados e quebradiços. Já os hidrogéis de alginato de cálcio, como já dito, apresentavam forma esférica e homogeneidade no tamanho. Assim, para dar continuidade ao trabalho, os grânulos sintetizados com cálcio se mostraram mais promissores. As fotografias dos grânulos de hidrogéis de alginato de cálcio e de alumínio estão ilustradas na Figura 1S.

\section{Influência da incorporação de nanocargas na matriz polimérica dos hidrogéis de alginato de cálcio}

O comportamento de intumescimento dos hidrogéis nanocompósitos foi determinado pelos valores de Q ( $\mathrm{g} / \mathrm{g})$ e Q (\%) e entre essas razões, obtidas para $\mathrm{Ca}^{2+}=1 ; 2,5$ e $5 \%$ sobre $\mathrm{Ca}^{2+}=1 \%$, em função do tempo de intumescimento (24h). A nanoargila cloisita- $\mathrm{Na}^{+}$, como já descrito, foi testada na concentração de $1 ; 2,5$ e $5 \%$. Na Tabela $1 \mathrm{~S}$ e na Figura 4 estão apresentados os resultados desse estudo.

Em relação à incorporação de nanoargila, é possível observar que na Figura $4 a$ o grau de intumescimento dos hidrogéis aumenta com o aumento da concentração de nanoargila. Além disso, para todos os nanocompósitos foi observado essa tendência na diminuição de Q com o incremento da concentração do agente reticulante. O 
Hidrogéis reticulados com cálcio

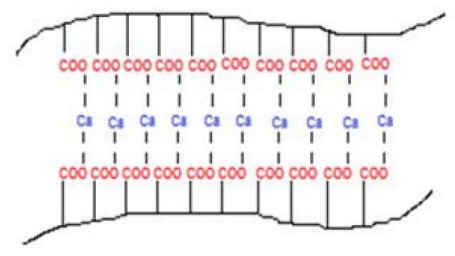

\section{Hidrogéis reticulados com alumínio}

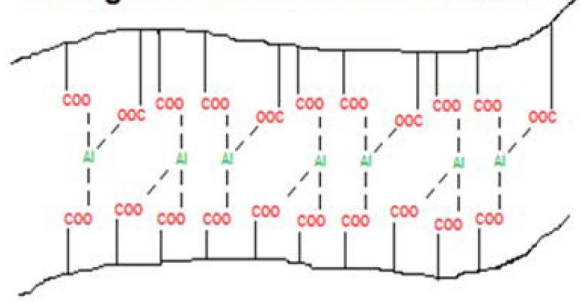

Figura 3. Mecanismo de reticulação para hidrogéis de alginato de cálcio e hidrogéis de alumínio

(a)

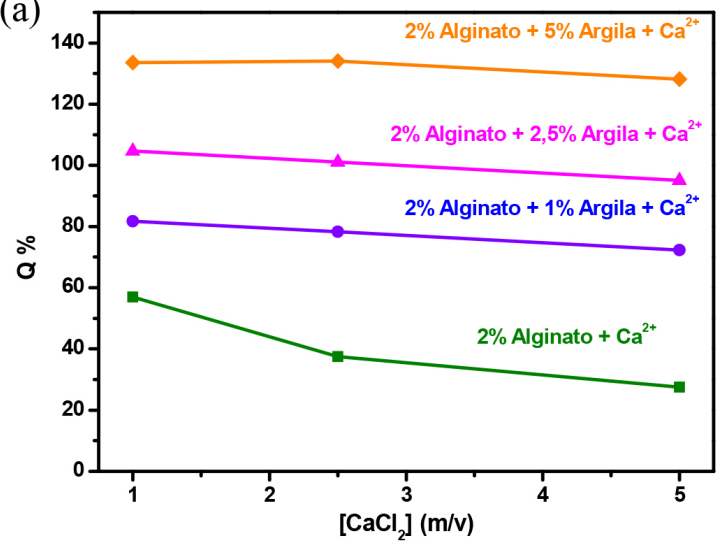

(b)

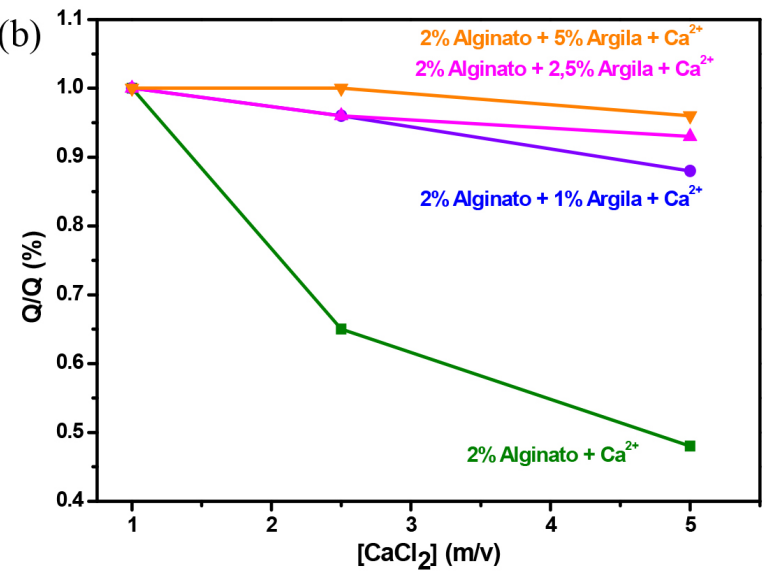

Figura 4. Dependência do grau de intumescimento em relação a diferentes concentrações de $\mathrm{Ca}^{2+}$ e de nanoargila (a). Relação de intumescimento para as diferentes concentrações do agente reticulador e nanoargila $(b)$

incremento no grau de intumescimento é atribuído à elevada capacidade de expansão e, consequentemente, boa capacidade de adsorção da nanoargila. As ligações iônicas presentes na nanoargila também podem estar influenciando, alojando também moléculas de água em seu interior. ${ }^{23-25}$ Observa-se também na Figura $5 b$ que em altas concentrações o agente reticulante não influência significativamente a capacidade de absorção de água.

Em relação à zeólita, a quantidade utilizada foi de $5 \%$ para síntese dos grânulos, Tabela 3. Ao analisar os dados da Tabela 3, observou-se que em algumas condições experimentais o grau de intumescimento do grânulos de hidrogéis com $5 \%$ de zeólita foi menor do que os valores do grau de intumescimento dos grânulos de hidrogéis puros (hidrogéis de alginato de cálcio) que estão apresentados na Tabela 1. Neste caso, mesmo a zeólita sendo um material hidrofílico, possivelmente esta deve estar atuando como um reticulador físico na matriz do hidrogel, na qual os grupos óxidos polares estabelecem interações físicas e/ou ligações de hidrogênio com os grupos carboxílicos ou hidroxílas, diminuindo assim a capacidade de expansão do hidrogel ${ }^{26}$ e refletindo em menor capacidade de absorção de água.

Por fim, em relação aos grânulos sintetizados com 2,5\% m/v de ambas as nanocargas, os valores do grau de intumescimento descritos na Tabela 4 e na Figura 5 diminuem com o incremento da concentração do agente reticulador.

Ao analisar a Figura 5, nota-se também que os valores de intumescimento dos grânulos nessas formulações apresentam valores intermediários aos grânulos sintetizados com $5 \% \mathrm{~m} / \mathrm{v}$ de nanoargila e com $5 \% \mathrm{~m} / \mathrm{v}$ de zeólita. Neste caso, a nanoargila $(2,5 \% \mathrm{~m} / \mathrm{v})$ auxilia na captação de moléculas de água para o interior da matriz, enquanto a zeólita $(2,5 \% \mathrm{~m} / \mathrm{v})$ atua como um reticulador físico na matriz do hidrogel, expulsando as moléculas de água.

Dentre os resultados apresentados, a nanoargila se mostrou mais eficiente no que se refere ao grau de intumescimento, visto que a
Tabela 3. Dados do grau de intumescimento dos hidrogéis com $2 \%$ de alginato + 5\% de zeólita e diferentes concentrações de cálcio

\begin{tabular}{ccc}
\hline \multicolumn{3}{c}{ Grânulos de hidrogéis de alginato de cálcio com 5\% de zeólita } \\
\hline$\left[\mathrm{CaCl}_{2}\right] \%(\mathrm{~m} / \mathrm{v})$ & $\mathrm{Q}(\mathrm{g} / \mathrm{g})$ & $\mathrm{Q}(\%)$ \\
\hline 1 & 1,39 & 39,41 \\
2,5 & 1,39 & 38,88 \\
5 & 1,38 & 38,11 \\
\hline & $\mathrm{Q} / \mathrm{Q}$ \\
\hline & $\mathrm{Q} / \mathrm{Q}(\mathrm{g} / \mathrm{g})$ & $\mathrm{Q} / \mathrm{Q}(\%)$ \\
$\mathrm{Q}_{1 \% \text { CaCl2 }} / \mathrm{Q}_{1 \% \text { CaCl2 }}$ & 1 & 1 \\
$\mathrm{Q}_{2,5 \% \mathrm{CaCl} 2} / \mathrm{Q}_{1 \% \mathrm{CaCl} 12}$ & 0,99 & 0,97 \\
$\mathrm{Q}_{5 \% \text { CaCl2 }} / \mathrm{Q}_{1 \% \text { CaCl2 }}$ & 0,99 & 0,93 \\
\hline
\end{tabular}

incorporação dessa aumentou tal propriedade. O efeito que provavelmente está relacionado é o fato que as moléculas de água estão interagindo simultaneamente com as nanocamadas da argila (majoritariamente) e também com os grupamentos hidrofílicos carboxílicos e hidroxilas provenientes da cadeia do alginato. Esse incremento é desejavel para aplicações em sistemas de liberação controlada de fármacos, pois acredita-se que a maior absorção de água pode levar à maior absorção de fármacos solúveis e, consequentemente, a uma maior taxa de liberação desse no organismo. Além disso, o uso de hidrogéis com nanoargila em sistemas de liberação controlada pode atingir o objetivo deste sistema, que é liberar o fármaco controladamente em níveis efetivos por longos períodos de tempo. Os tipos de interações estabelecidas entre nanoargila-fármaco são muito importantes, visto que tais interações não devem ser fortes (covalente) e nem fracas, isso porque interações fortes entre ambos podem dificultar a 
Tabela 4. Valores do grau de intumescimento dos hidrogéis de alginato sintetizados com $2,5 \% \mathrm{~m} / \mathrm{v}$ de nanoargila e zeólita

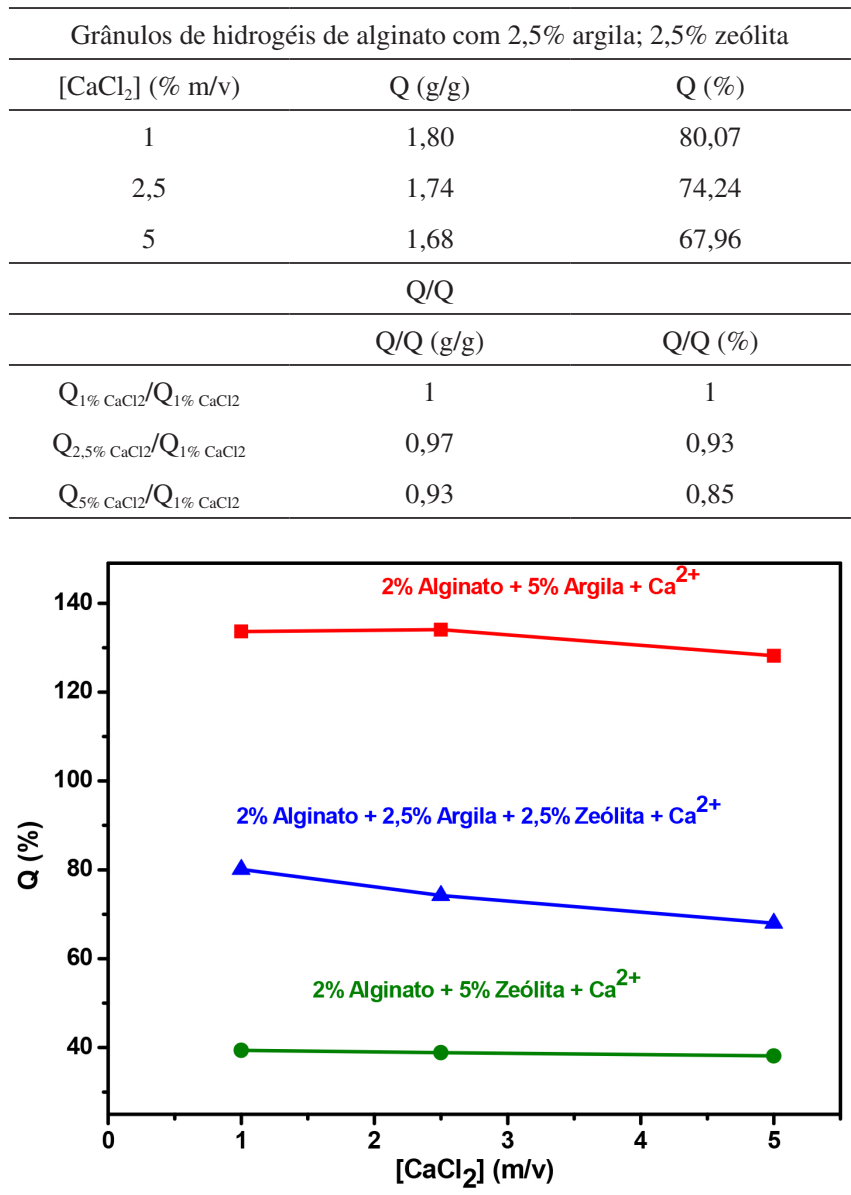

Figura 5. Comportamento de intumescimento de hidrogéis nanoestruturados com 5\% de argila; $5 \%$ de zeólita e mistura de ambas as nanocargas nas concentrações de $2,5 \% \mathrm{~m} / \mathrm{v}$ para cada uma delas

liberação do fármaco e no caso de interações fracas o fármaco pode ser liberado rapidamente.

Os nanocompósitos contendo zeólita se mostraram menos promissores para fármacos solúveis, visto que o grau de intumescimento em algumas condições são menores que os grânulos de hidrogéis puros. Pensando no meio de aplicação do presente trabalho, graus de intumescimento mais elevados são interessantes, uma vez que poderiam aumentar a quantidade de fármaco carregada e assim diminuir ainda mais o número de dosagens a serem ministradas. Por outro lado, nanocompósitos contendo zeólita também serão investigados futuramente em relação a sua potencialidade de aplicação em sistemas de liberação de fármacos, pois o fato de absorverem menor quantidade de água pode implicar em uma maior interação com fármacos menos solúveis, ou seja, pode potencializar o processo de dessorção controlada.

\section{Difração de raios-X}

Como já descrito anteriormente, esta técnica foi utilizada para avaliar a conformação (estruturação) da nanoargila na matriz polimérica, definindo assim o tipo de nanocompósito obtido, intercalado ou esfoliado. Para materiais compósitos intercalados, o pico característico da nanoargila se desloca para menores valores de $2 \theta$, ao passo que para materiais compósitos esfoliados o pico característico da nanoargila nao é observado no difratograma (provavelmente apareceria para $2 \theta<4^{\circ}$ ). Na Figura $6 a$ está apresentado o difratograma de raios- $\mathrm{X}$ contendo as curvas representativas do comportamento do alginato de sódio, do hidrogel de alginato de cálcio, da nanoargila cloisita-Na ${ }^{+}$e dos hidrogéis nanocompósitos. A Figura $6 b$ é uma ampliação do difratograma da Figura $6 a$ com as curvas representativas
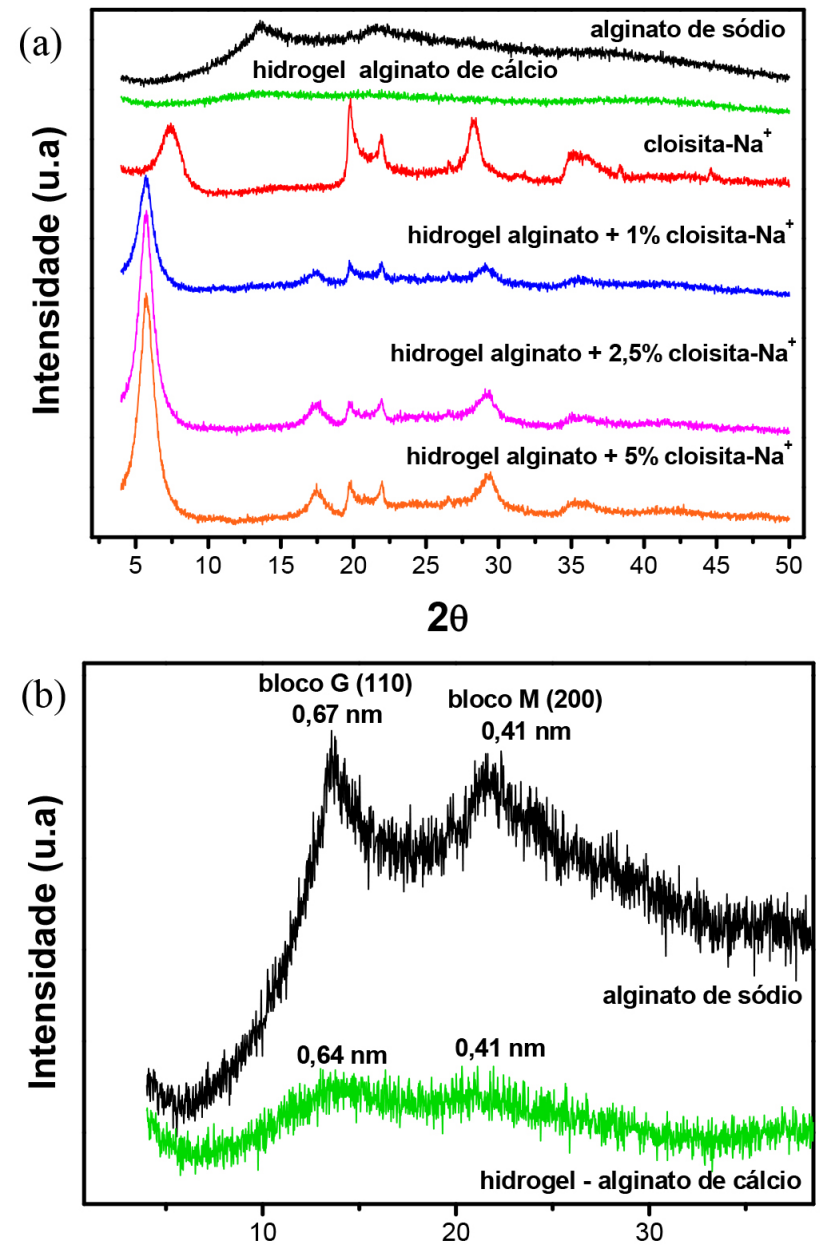

20



Figura 6. Difratograma de raios-X do alginato de sódio, da nanoargila, do hidrogel puro e do hidrogel nanocompósito (a); ampliação das curvas do alginato e do hidrogel nanocompósito nas regiões dos picos característicos (b) e ampliação das curvas da nanoargila e dos nanocompósitos nas regiões do pico característicos do plano (001) (c) 


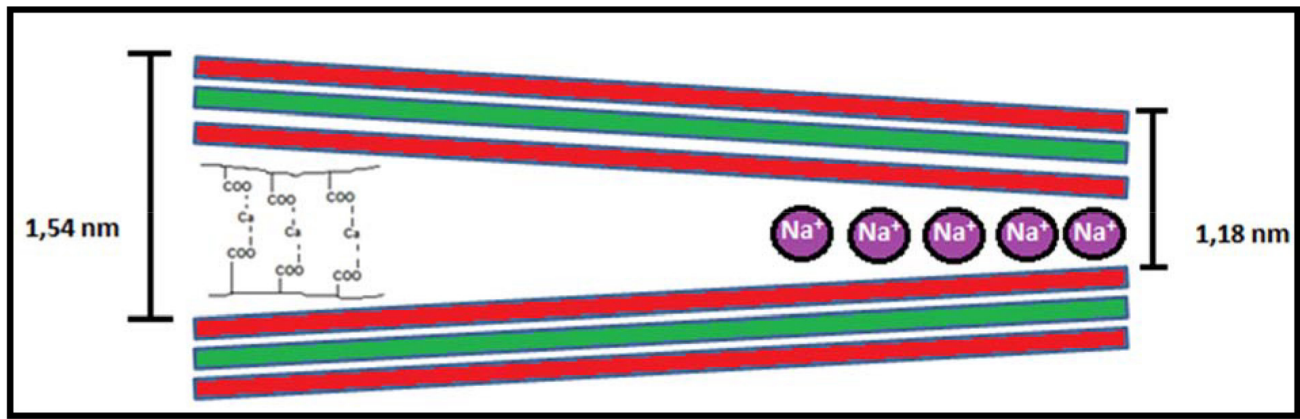

Figura 7. Representação esquemática do espaçamento basal da nanoargila cloisita-Na+ com íons de sódio e com os hidrogéis entre as plaquetas. As linhas vermelhas são referentes as camadas tetraédricas e a linha verde refere se a camada octaédrica

do comportamento do alginato de sódio e do hidrogel de alginato de cálcio, apresentando picos característicos de difração desses e a Figura $6 c$ é uma ampliação da Figura $6 a$ das curvas da cloisita- $\mathrm{Na}^{+}$ e dos nanocompósitos.

Para as curvas do alginato de sódio e do hidrogel de alginato de cálcio, foram observados picos e alargamentos, que ficam evidentes na Figura $6 b$. Os picos do alginato de sódio não são análogos, pelo fato do padrão de difração do alginato de sódio estar associado com a disposição dos grupos $\mathrm{G}$ e $\mathrm{M}$ na cadeia polimérica e a composição química. Para o ácido $\beta$-D-manurônico referente ao bloco $\mathrm{M}$, os sinais de difração são atribuídos a uma célula unitária ortorrômbica, na qual duas cadeias ou planos estão organizados paralelamente na direção horizontal compreendendo as dimensões de: $\mathrm{a}=0,76 \mathrm{~nm}$, $\mathrm{b}=0,86 \mathrm{~nm}$ e $\mathrm{c}=1,04 \mathrm{~nm}$. Já para o bloco $\mathrm{G}$ condizente com o ácido $\alpha$-L-gulurônico, os sinais de difração são atribuídos também a uma célula unitária ortorrômbica, em que as cadeias estão dispostas paralelamente na direção vertical, cujas dimensões são de: $\mathrm{a}=0,86 \mathrm{~nm}$, $\mathrm{b}=1,07 \mathrm{~nm}$ e $\mathrm{c}=0,87 \mathrm{~nm}$. O plano cristalino de difração para o bloco $\mathrm{M}$ é referente ao plano (200) e para o bloco G o plano é (110). ${ }^{27,28}$ Com relação ao hidrogel de alginato de cálcio observam-se 2 alargamentos. O primeiro encontra se na região de $13,92^{\circ}$ em $2 \theta$ e o outro na região de $21,22^{\circ}$. Essas características são atribuídas a materiais amorfos e já eram esperadas pelo fato do hidrogel ser um material amorfo (material reticulado).

Para a nanoargila pura observam-se vários picos de difração. O pico característico do plano cristalino (001) foi encontrado em $7,4^{\circ}$ em $2 \theta$ e este pico apresentou o espaçamento basal $\mathrm{d}_{001}=1,18 \mathrm{~nm}$. Os demais picos observados na curva referem-se ao componente quartzo identificado na maioria dos minerais. Para os hidrogéis nanocompósitos, o pico de difração característico da nanoargila do plano (001) foi identificado em $2 \theta=5,7^{\circ}$ para todas as formulações. Portanto, o espaçamento basal (001) da nanoargila aumentou de 1,18 nm para 1,54 nm nos hidrogéis nanocompósitos. Esse aumento no espaçamento basal é um forte indício que a nanoargila está de forma intercalada na matriz do hidrogel, sendo que intercalações promovem a diminuição no ângulo $2 \theta$ e, consequentemente, o aumento do espaçamento basal. ${ }^{29-32}$ Este aumento do espaçamento interlamelar pode estar atribuído à dimensão das cadeias poliméricas do hidrogel, que para os autores o hidrogel está alojando entre as plaquetas, expulsando os íons de sódio, como ilustrado na Figura 7.

\section{CONCLUSÃO}

A síntese e a otimização dos hidrogéis englobaram diversos fatores e o critério utilizado para definir a melhor formulação foi o grau de intumescimento e a homogeneidade das microesferas. Sendo assim, os hidrogéis síntetizados com $2 \%(\mathrm{~m} / \mathrm{v})$ de alginato de sódio apresentaram grau de intumescimento satisfatório, além do que o aspecto físico foi totalmente esférico e de tamanho homegêneo, aspectos esses não apresentados pelos grânulos com $1 \%(\mathrm{~m} / \mathrm{v})$ de alginato. Com relação ao agente reticulador, a escolha do cloreto de cálcio se deu pela inconstância dos valores de intumescimento apresentado pelos hidrogéis de alginato de alumínio.

Os grânulos de alumínio estavam mais quebradiços, de difícil manuseamento, deformados e de tamanho não uniforme, fatores que também implicaram na definição do cloreto de cálcio como agente reticulador do trabalho. Com a concentração do polissacarídeo e o agente reticulador definidos, a obtenção dos hidrogéis nanocompósitos se tornou possível. Por meio da análise do grau de intumescimento dos nanocompósitos, observou-se que a nanoargila contribuiu para o aumento do grau de intumescimento se comparado com hidrogéis controle (alginato de cálcio). Por outro lado, a zeólita contribuiu de maneira menos satisfatória para essa propriedade. Por meio da técnica de DRX, foi possível determinar a conformação da nanoargila na matriz do hidrogel, sendo esta incorporada de maneira intercalada nas formulações apresentadas. Portanto, foi possível alcançar a melhor rota de síntese, incluíndo os materiais e as concentrações a serem utilizadas. A síntese de hidrogéis à base do polissacarídeo alginato de sódio se mostrou promissora para que esses materiais possam ser testados como veículos carreadores em sistemas de liberação de solutos voltados para a área médica.

\section{MATERIAL SUPLEMENTAR}

No material suplementar, disponível gratuitamente em http://quimicanova.sbq.org.br na forma de arquivo PDF, estão apresentadas na Figura 1S algumas fotografias digitais capturadas após o processo de diálise dos grânulos. A fotografia (a) se refere aos hidrogéis de alginato de cálcio e a (b) se refere aos hidrogéis de alginato de alumínio. Na Tabela $1 \mathrm{~S}$ são apresentados resultados de grau de intumescimento para diferentes concentrações de nanoargila incorporada nos grânulos de hidrogéis de alginato de cálcio.

\section{AGRADECIMENTOS}

Os autores agradecem à Unesp, ao Conselho Nacional de Desenvolvimento Científico e Técnológico (CNPq) e à Fundação de Amparo à Pesquisa do Estado de São Paulo (FAPESP) pela bolsa que fomentou essa pesquisa e pelo suporte financeiro.

\section{REFERÊNCIAS}

1. Amaral, R. H.; Dissertação de mestrado, Instituto de Pesquisa Energética e Nucleares, Brasil, 2009.

2. Canevarolo Jr., S. V.; Em Ciência dos Polímeros; Canevarolo Jr., S. V., ed.; Artliber: São Paulo, 2006, cap. 1.

3. Comaposada, J.; Gou, P.; Marcos, B.; Arnau, J.; LWT - - Food Sci. Technol. 2015, 64, 212. 
4. Lee, K. Y.; Mooney, D. J.; Prog. Polym. Sci. 2012, 37, 107.

5. Hay, I. D.; Rehman, Z. U.; Ghafoor, A.; Rehm, B. H. A.; J. Chem. Technol. Biotechnol. 2010, 85, 753.

6. Turniani, F. R. B.; Kieckbusch, T. G.; Braz. J. Food Technol. 2011, 14, 83

7. Santana, G. C.; Dissertação, Universidade Federal de Sergipe, Brasil, 2012.

8. Paiva, L. B. de; Morales, A. R.; Díaz, F. R. V.; Ceramica (Sao Paulo, Braz.) 2008, 54, 214.

9. Coelho, A. C. V.; Santos, P. S. de; Santos, H. S. de; Quim. Nova 2007, $30,146$.

10. Carretero, M. I.; Appl. Clay Sci. 2002, 21, 155.

11. Garcia, C. P.; Dissertação, Universidade do Estado do Rio de Janeiro, Brasil, 2010.

12. Johnson, E. B. G.; Arshad, S. E.; Appl. Clay Sci. 2014, 97-98, 215.

13. Vieira, L. H.; Rodrigues, M. V.; Martins, L.; Quim. Nova 2014, 37, 1515.

14. Aouada, F. A.; Moura, M. R. de; Fernandes, P. R. G.; Rubira, A. F.; Muniz, E. C.; Quim. Nova 2014, 37, 1302.

15. Lin, C. C.; Metters, A. T.; Adv. Drug Delivery Rev. 2006, 58, 1379.

16. Ullah, F.; Othman, M. B. H.; Javed, F.; Ahmad, Z.; Akil, H. M.; Mater. Sci. Eng., C 2015, 57, 414.

17. Lyra, M. A. M. de; Sobrinho, J. L. S.; Brasileiro, M. T.; Roca, M. F. L. de; Barraza, J. A.; Viana, O. S. de; Neto, P. J. R.; Lat. Am. J. Pharm. 2007, 26, 785 .

18. Zhou, Y.; Fu, S.; Zhang, L.; Zhan, H.; Carbohydr. Polym. 2013, 97, 435.
19. Gonzales, J. S.; Ludeña, L. N.; Ponce, A.; Alvarez, V. A.; Mater. Sci. Eng. 2014, 34, 61

20. Yadollahi, M.; Gholomali, I.; Namazi, H.; Aghazadeh, M.; Int. J. Biol. Macromol. 2015, 74, 141

21. Huang, X.; Xiao, Y.; Lang, M.; Carbohyd. Polym. 2012, 87, 793.

22. Li, Y.; Hu, M.; Du, Y.; Xiao, H.; Mcclements, D. J.; Food Hydrocolloids 2011, 25, 125

23. Barreca, S.; Orecchio, S.; Pace, A.; Appl. Clay Sci. 2014, 99, 221.

24. Kaygusuz, H.; Erim, F. B.; React. Funct. Polym. 2013, 73, 1420.

25. Iliescu, R. I.; Andronescu, E.; Ghitulica, C. D.; Voicu, G.; Ficai, A.; Hoteteu, M.; Int. J. Pharm. 2014, 463, 185.

26. Rashidzadeh, A.; Olad, A.; Salari, D.; Reyhanitabar, A.; J. Polym. Res. 2014, 344, 4.

27. Nery, J. C.; Dissertação, Centro Federal de Educação Tecnológica de Minas Gerais, Brasil, 2014.

28. Sundarrajaran, P.; Eswaran, P.; Marimuthu, A.; Subhadra, L. B.; Kannaiyan, P.; Bull. Korean Chem. Soc. 2012, 33, 3221.

29. Mallakpour, S.; Shahangi, V.; Polym. Sci., Ser. B 2013, 55, 47.

30. Wokadala, O. C.; Ray, S. S.; Bandyopadhyay, J.; Wesley-Smith, J.; Emmambux, N. M.; Polymer 2015, 71, 85.

31. Gonçalves, W. P.; Silva, V. J.; Gomes, J.; Menezes, R. R.; Nevez, G. A.; Ferreira, H. C.; Santana, L. N. L.; Ceramica (Sao Paulo, Braz.) 2014, 60,318 .

32. Oliveira, A. D. de; Castro, L. D. C. de; Jung, M. K.; Pessan, L. A.; Polim.: Cienc. Tecnol. 2015, 25, 222. 